\title{
Treating COPD Patients with Inhaled Medications in the Era of COVID-19 and Beyond: Options and Rationales for Patients at Home
}

\author{
Arzu Ari iD ' \\ Karen Blain ${ }^{2}$ \\ Said Soubra' \\ Nicola A Hanania ${ }^{3}$ \\ 'Department of Respiratory Care, Texas \\ State University, Round Rock, TX, USA; \\ ${ }^{2}$ Department of Respiratory Therapy, \\ University of North Carolina \\ Wilmington, Wilmington, NC, USA; \\ ${ }^{3}$ Airways Clinical Research Center, Baylor \\ College of Medicine, Houston, TX, USA
}

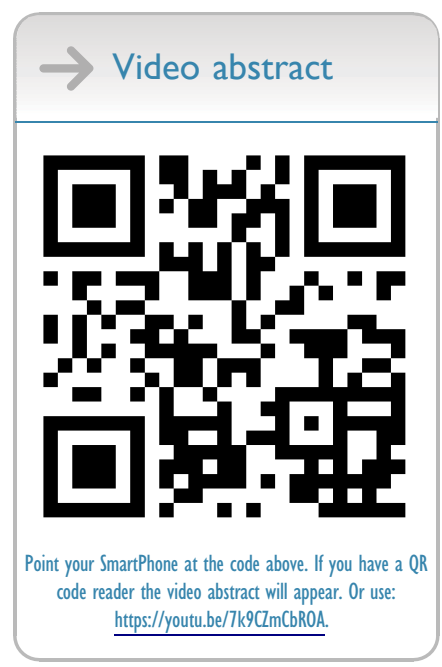

Correspondence: Arzu Ari Email arzuari@txstate.edu

\begin{abstract}
COVID-19 has affected millions of patients, caregivers, and clinicians around the world. Severe acute respiratory syndrome coronavirus 2 (SARS-CoV-2) spreads via droplets and close contact from person to person, and there has been an increased concern regarding aerosol drug delivery due to the potential aerosolizing of viral particles. To date, little focus has been given to aerosol drug delivery to patients with COVID-19 treated at home to minimize their hospital utilization. Since most hospitals were stressed with multiple admissions and experienced restricted healthcare resources in the era of COVID-19 pandemic, treating patients with COPD at home became essential to minimize their hospital utilization. However, guidance on how to deliver aerosolized medications safely and effectively to this patient population treated at home is still lacking. In this paper, we provide some strategies and rationales for device and interface selection, delivery technique, and infection control for patients with COPD who are being treated at home in the era of COVID-19 and beyond.
\end{abstract}

Keywords: coronavirus, COVID-19, SARS-CoV-2, aerosols, nebulizers, inhalers, homecare, infection control

\section{Introduction}

COVID-19 was caused by SARS-CoV-2, a novel coronavirus, that affected millions of people worldwide as this respiratory illness is transmitted from person to person via droplets and close contacts. ${ }^{1}$ It has been known that respiratory viruses trigger COPD exacerbations and cause deterioration of the patients' symptoms. ${ }^{2}$ While aerosolized medications are commonly used in the treatment of patients with COPD, there has been an increased concern regarding aerosol drug delivery to patients with COVID-19 due to the potential aerosolization of viral particles especially within the hospital setting. While hospitals were stressed with many patient admissions and there was so much discussion on the management of critically ill patients with the limited healthcare resources during the COVID-19 pandemic, little focus has been given to management strategies and guidance to clinicians and patients with chronic pulmonary diseases who are treated at home. Evidence based guidance on how to deliver aerosolized medications safely and effectively to this patient population treated at home is still lacking. The purpose of this review is to discuss some strategies and provide potential rationales for device selection, interface selection, delivery technique, and infection control for managing patients with COPD at home in the era of COVID-19 and beyond. 
Previous research reported that the severe acute respiratory syndrome (SARS) coronavirus and the middle east respiratory syndrome coronavirus (MERS-CoV) presented with similar clinical features and outcomes to that of COVID-19. ${ }^{3}$ Due to the findings of previous research that revealed high-risk for MERS-CoV in asthma, ${ }^{4}$ patients with chronic pulmonary diseases were also considered to be at an increased risk for COVID-19. However, this assumption has not been demonstrated in several reports and conflicting evidence exists on the risk and potential consequences of COVID-19 in this population. ${ }^{5}$ Halpin et al demonstrated that the prevalence of asthma and COPD was lower in patients diagnosed with COVID-19. ${ }^{6}$ The authors postulated that this may be due to the treatments used in chronic pulmonary diseases such as inhaled corticosteroids which may reduce not only the risk of infection but also the development of severe symptoms in COVID-19. Indeed, the Global Initiative for Asthma (GINA) and Global Initiative for Obstructive Lung Diseases (GOLD) strategies continue to recommend the use of prescribed inhaled medications in asthma and COPD to prevent worsening of disease symptoms and severity. ${ }^{7,8}$ According to previous research, 40$60 \%$ of COPD exacerbations are due to viral infections. ${ }^{2}$ Since having COPD is considered an underlying condition that may be associated with disease severity, it is vital to advise patients with COPD to continue taking their inhaled medications at home to control disease symptoms and prevent exacerbation of their disease. ${ }^{9}$ However, patient outcomes from aerosol therapy depend on the compatibility of patient characteristics with the features of the aerosol device selected for the treatment.

\section{Device Selection}

Several factors affect device selection for inhaled medications. Of importance are patient characteristics such as age, degree of obstruction, physical and cognitive abilities, as well as patient preference. Furthermore, features of the aerosol device such as availability, cost, reimbursement, and convenience of use are crucial. ${ }^{10-13}$ Aging decreases peak inspiratory flow rate (PIFR) and leads to an increased risk of ineffective inhalations with inhalers. ${ }^{14,15}$ In addition, the patient error in the use of inhalers increases with the degree of airway obstruction. ${ }^{14,16}$ Therefore, regular inhalers may not be appropriate for elderly patients with severe COPD. Many host factors increase the risk of critical errors during aerosol drug delivery with inhalers. These factors include impairment in manual dexterity, decreased respiratory muscle strength, impaired hearing, visual deficits, loss of physical strength in hand and finger muscles, cognitive dysfunction, and co-morbidities such as neuromuscular conditions. Inadequate hand strength may lead to an inability to use pressurized metered-dose inhalers (pMDIs). Furthermore, dry powder inhalers (DPIs) may not be ideal for this patient population due to impairment in manual dexterity and a low PIFR. Patients will have a hard time placing the unit dose medication into the reservoir of the device and use the unitdose DPI effectively. While visual deficits may affect proper loading of the inhaler and the ability to see the dose counter, patients with hearing deficits may not apprehend the "click" sound indicating readiness to inhale through a DPI. Decreased respiratory muscle strength may also reduce the patient's ability to generate the minimum flow and volume needed to operate inhalers correctly. ${ }^{17}$ Therefore, the patient's potential to understand how and when to use an aerosol device should be evaluated regularly to determine their cognitive ability. Failure on cognitive testing indicates that regular inhalers might be inappropriate for the patient. ${ }^{17}$ Patient preference is linked to good inhalation techniques that improve patient adherence to the prescribed therapy. ${ }^{18-}$ ${ }^{20}$ Patients prefer an aerosol device that is small, portable, and easy to use. If an aerosol device has a short treatment time, requires less cleaning/maintenance, and is the least-out-ofpocket expense for the patient, it is considered convenient. Therefore, the preference of patients and the convenience of the device are other important factors that need to be considered in device selection. However, only 35 to $37 \%$ of healthcare providers considered the type of aerosol device to be highly important when prescribing inhaled drugs for newly diagnosed stable patients with COPD and those with post exacerbations. ${ }^{21}$ Also, healthcare providers prioritize inhaled medication over the device when selecting treatments while showing limited attention to the proper use of aerosol devices. ${ }^{21}$

While it is important to avoid unnecessary aerosol therapy in patients with COPD who were tested positive for infectious diseases such as COVID-19, clinicians need to select the right device, the right interface, and the right medication for the right patient who needs to be treated with aerosolized medications in the era of COVID-19 and beyond. Therefore, clinicians should be trained in device selection, interface selection, delivery technique, device preparation, cleaning, and maintenance (Table 1). For instance, inhalers should be preferred over nebulizers to minimize aerosolization unless the patient cannot perform specific breathing techniques needed to use the prescribed inhaler effectively. ${ }^{22,23}$ Effective aerosol therapy with pMDIs 
Table I Options and Rationales for Aerosol Drug Delivery to Patients with COPD Who are Diagnosed with COVID-19 and Treated at Home

\begin{tabular}{|c|c|c|}
\hline & Options & Rationales \\
\hline \multirow[t]{3}{*}{$\begin{array}{l}\text { Device } \\
\text { Selection }\end{array}$} & $\begin{array}{l}\text { Prefer inhalers over nebulizers except for the following } \\
\text { three conditions: } \\
\text { (I) The patient cannot perform specific breathing techniques } \\
\text { needed for inhalers, } \\
\text { (2) The drug formulation is not available as inhalers, or } \\
\text { (3) There is a shortage of inhalers. }\end{array}$ & $\begin{array}{l}\text { - Exhaled air dispersion and virus transmission with inhalers } \\
\text { may be lower than jet nebulizers due to their low emitted } \\
\text { dose and less aerosol mass generation. }\end{array}$ \\
\hline & $\begin{array}{l}\text { - Do not use the dry powder inhalers (DPI) if the patient } \\
\text { cannot generate a high inspiratory rate needed to use the } \\
\text { device effectively or if the DPI causes airway irritation or } \\
\text { cough during aerosol therapy. }\end{array}$ & $\begin{array}{l}\text { - Coughing will increase exhaled air dispersion and virus trans- } \\
\text { mission. Patients who cannot generate a high inspiratory } \\
\text { flow rate will not disperse the drug particles and draw the } \\
\text { drug from the device. }\end{array}$ \\
\hline & $\begin{array}{l}\text { - Prefer mesh nebulizers instead of jet nebulizers if you need } \\
\text { to use a nebulizer when one of the three conditions listed } \\
\text { above applies. Another option is to use breath actuated } \\
\text { nebulizers that generate aerosols only in inspiration. }\end{array}$ & $\begin{array}{l}\text { - Unlike mesh nebulizers, jet nebulizers release } 2 / 3 \text { of the } \\
\text { aerosols generated by the device and disperse them to the } \\
\text { environment due to the external gas flow needed for their } \\
\text { operation. }\end{array}$ \\
\hline $\begin{array}{l}\text { Interface } \\
\text { Selection }\end{array}$ & $\begin{array}{l}\text { - Prefer a mouthpiece over a face mask to reduce fugitively } \\
\text { emitted aerosol concentration. }\end{array}$ & $\begin{array}{l}\text { - Unlike the face mask, the mouthpiece will not force aerosol } \\
\text { out of the interface during therapy. }\end{array}$ \\
\hline \multirow[t]{3}{*}{$\begin{array}{l}\text { Device } \\
\text { Preparation }\end{array}$} & $\begin{array}{l}\text { - Wash your hands with soap and water for } 20 \text { seconds or use } \\
\text { an alcohol-based hand sanitizer that contains at least } \% 60 \\
\text { alcohol before and after aerosol therapy. }\end{array}$ & $\begin{array}{l}\text { - Washing hands will help minimize the contamination of the } \\
\text { aerosol device and medication during device preparation, } \\
\text { cleaning and maintenance. }\end{array}$ \\
\hline & $\begin{array}{l}\text { - The risk of contamination during device preparation is lower } \\
\text { with inhalers compared to jet nebulizers. }\end{array}$ & $\begin{array}{l}\text { - Because the drug is enclosed, it is hard to contaminate the } \\
\text { inhaler during device preparation, unlike jet nebulizer that } \\
\text { has a high risk of transmission if patient's secretion drops in } \\
\text { the nebulizer reservoir due to their open design. }\end{array}$ \\
\hline & $\begin{array}{l}\text { - Mesh nebulizers may be a good alternative for aerosol ther- } \\
\text { apy if nebulizers need to be used COVID-19 positive patients } \\
\text { with COPD. }\end{array}$ & $\begin{array}{l}\text { - Since mesh nebulizers separate the medication from the } \\
\text { patient interface through the mesh, it is hard to contami- } \\
\text { nate the mesh nebulizer with the patient's secretion. }\end{array}$ \\
\hline \multirow[t]{4}{*}{$\begin{array}{l}\text { Delivery } \\
\text { Technique }\end{array}$} & $\begin{array}{l}\text { - Use the pMDI with a valved holding chamber (VHC) that has } \\
\text { a mouthpiece. }\end{array}$ & $\begin{array}{l}\text { - Using a VHC with a mouthpiece will minimize the need for } \\
\text { hand-breath coordination and oropharyngeal deposition. }\end{array}$ \\
\hline & - Place a filter to the outlet of a nebulizer. & $\begin{array}{l}\text { - The filter will capture exhaled droplets and reduce aerosol } \\
\text { concentration in the environment. }\end{array}$ \\
\hline & $\begin{array}{l}\text { - Use the aerosol device based on the manufacturer's } \\
\text { guidelines. }\end{array}$ & $\begin{array}{l}\text { - Following the manufacturing guidelines will improve delivery } \\
\text { technique, treatment efficiency and safety. }\end{array}$ \\
\hline & $\begin{array}{l}\text { - Administer aerosol therapy in a location such as outside on } \\
\text { a patio, porch, or in a garage, where the air is not circulated } \\
\text { into the house. }\end{array}$ & $\begin{array}{l}\text { - It will minimize the dispersion of exhaled air in the house and } \\
\text { the risk of virus transmission to family members. }\end{array}$ \\
\hline $\begin{array}{l}\text { Device } \\
\text { Cleaning \& } \\
\text { Maintenance }\end{array}$ & $\begin{array}{l}\text { - Replace disposable nebulizers once every } 24 \text { hours. } \\
\text { - Clean reusable jet nebulizers with soap and water, rinse, } \\
\text { - Clean mesh nebulizers based on the manufacturers' } \\
\text { guidelines. }\end{array}$ & $\begin{array}{l}\text { - Regular device cleaning and maintenance will help minimize } \\
\text { device contamination and the risk of virus transmission. }\end{array}$ \\
\hline
\end{tabular}


requires optimum delivery technique by achieving good hand-breath coordination, actuating the pMDI at the beginning of inspiration, breathing slowly, and holding the breath at the end of inspiration. ${ }^{10-12,24,25}$ Since patients were concerned about medication effectiveness but not with proper inhalation technique, ${ }^{21,26} 92 \%$ of patients with COPD and asthma make at least one error in their inhalation technique. ${ }^{27}$ In patients with poor technique, while using pMDIs, the use of valved-holding chambers should be encouraged. If patients are still unable to make the required steps for optimum technique with pMDIs, DPIs should be considered to deliver inhaled medications to patients who can achieve adequate inspiratory flow rate needed for the specific device. ${ }^{9,22,23}$ Since each DPI requires a different inspiratory flow rate for optimum aerosol drug delivery, ${ }^{28}$ evaluating patient ability and performance as well as patient education and follow-up is vital to achieving optimum disease management in COPD. ${ }^{24}$

Unfortunately, there was a shortage of inhalers during the COVID-19 pandemic in the United States. ${ }^{29,30}$ When a drug formulation is not available as an inhaler or patients cannot perform the specific breathing techniques with inhalers, aerosolized medications can be delivered through nebulizers. ${ }^{9,22,23}$ Different types of nebulizers are available and include: (1) Jet nebulizers, and (2) mesh nebulizers. ${ }^{31}$ While jet nebulizers are less expensive than mesh nebulizers, two-third of the aerosols generated by the jet nebulizer are delivered to the environment ${ }^{31-34}$ that may put other family members at risk of infection if the device is contaminated. In this case, using breath-actuated jet nebulizers could be a good option because they generate aerosols only during inspiration as opposed to conventional jet nebulizers that generate aerosols continuously during the entire breathing cycle. ${ }^{35}$ Therefore, the release of exhaled aerosols into the environment with breath-actuated nebulizers is less than conventional nebulizers. Another alternative is to use the mesh nebulizer for aerosol therapy in the era of COVID-19. Since mesh nebulizers separate the medication from the patient interface through the mesh, the risk of device contamination in mesh nebulizers is lower than conventional jet nebulizers. Also, mesh nebulizers operate with electrical mains instead of external gas flow that contributes to the dispersion of patient-generated bioaerosol into the atmosphere. ${ }^{23}$

\section{Interface Selection}

Interface selection is as important as device selection in patients with COPD treated at home in the era of COVID-
19. The right interface is the one that is tolerated and preferred by the patient. It is the interface that is used reliably during aerosol therapy. Therefore, clinicians should consider each interface that can be combined with the aerosol device selected for the patient's treatment. For instance, pMDIs are used with spacers or valved holding chambers (VHCs). Although spacers and VHCs are designed to improve the delivery efficiency of pMDIs, they differ in their design. VHCs have one-way valves that contain aerosol until the patient's inspiration, while spacers are simple tubes without valves and require some hand-breath coordination. Also, exhaling in the spacer after actuating the pMDI wastes most of the dose to the environment. Therefore, pMDIs should be combined with VHCs to decrease oropharyngeal deposition and the need for hand-breath coordination during aerosol therapy. Multiple actuations into the spacer or VHC will reduce drug delivery to patients with COPD ${ }^{36,37}$ Also, clinicians should be aware of the issue with the electrostatic charge of spacers and VHCs that will decrease inhaled dose by the patient. While one alternative is to wash spacers with detergent to eliminate electrostatic charge, ${ }^{38-42}$ another option is to use a non-electrostatic spacer for aerosol therapy if possible. ${ }^{43}$

When a nebulizer is used for aerosol drug delivery for patients with COVID-19, a mouthpiece is preferred over a face mask because it will not force aerosol out of the interface in expiration and breath-hold. ${ }^{22,23,44}$ Therefore, the mouthpiece has less fugitively emitted aerosol concentration compared to the face mask and attaching a filter to the exhalation port of the mouthpiece reduces the dispersion of exhaled bioaerosols to the environment. ${ }^{45}$

\section{Delivery Technique}

Aerosol delivery with inhalers requires several steps. For instance, shaking, priming, hand-breath coordination, and breath-hold are crucial for the effective use of pMDI during aerosol therapy. ${ }^{46}$ While shaking and priming the pMDI before the treatment ensures a homogeneous mixture of the medication and proper filling of the metering chamber before actuation, it is also essential to coordinate pMDI actuation with inhalation, breath slowly, and hold the breath after inhalation. Common errors with the pMDI include inadequate shaking/priming, failure to coordinate pMDI actuation with inhalation, actuating pMDI during expiration, rapid inhalation after actuation, firing pMDI multiple times during single inhalation, actuating the pMDI into the mouth but inhaling through the nose, and inadequate or no breath-hold after inhalation. ${ }^{36,46-50}$ 
While DPIs eliminate some of these problems related to the delivery technique with pMDIs, they have their own challenges such as using the DPI in wrong orientation during device preparation or treatment, failure to pierce the blister package or capsule before inhalation, shaking the device, exhalation into the DPI, or inadequate inspiratory flow rate. Each DPI has a specific requirement for the inspiratory flow rate to draw the medication from the inhaler and to disaggregate the powder into small particles. Adequate inspiratory flow rate leads to better disaggregation and greater lung deposition with the DPI. However, elderly patients with COPD may not have the physical ability to generate the adequate inspiratory flow required by the DPI. Clinicians can determine the best inhaler for their patients by using a hand-held inspiratory flow meter such as In-Check-Dial (Clement Clarke International Ltd, UK) that simulates the resistance of common inhalers. ${ }^{24,51,52}$ Such hand-held inspiratory flow meters could be used for inhaler selection and patient education on using the inhaler correctly. ${ }^{51-55}$ Also, previous research showed that humidity from patient exhalation or in the ambient environment result in powder clumping and reduce the delivery efficiency of the DPI. ${ }^{18,46}$

The delivery technique with nebulizers is simple. Unlike pMDIs and DPIs, it does not require any specific breathing technique and only normal tidal breathing is adequate for effective aerosol delivery during the treatment with nebulizers.

\section{Infection Control and Prevention}

The transmission of COVID-19 is through droplets generated as bioaerosols that remain viable and infectious for hours. While larger aerosol particles fall to the ground, small ones remain in the air and spread with air currents. Also, it is difficult to differentiate bioaerosols from medical aerosols. Bioaerosols are generated by patients during talk, cough, sneeze, or sing. If a patient is diagnosed with COVID-19, his/her exhaled bioaerosols may contain the pathogen and play a prominent role in the spread of coronavirus. On the other hand, medical aerosols are produced by the aerosol device used during treatment. Also, medical aerosols that are not inhaled by the patient but pass into the atmosphere are defined as fugitive emissions. Although aerosol therapy generates fugitive emissions, they are medical aerosols generated by aerosol devices as opposed to bioaerosols produced by patients. ${ }^{9,22,23} 50 \%$ of medical aerosols generated during aerosol therapy is fugitive emissions that have a particle size between 0.860 and $1.437 \mu \mathrm{m}^{45,56-59}$ The quantity and characteristics of fugitive emissions are influenced by many factors such as flow rate, the type of aerosol device and interface used during therapy. ${ }^{58,60,61}$ Temperature, air turbulence, and airflow rates as well as the size and layout of the room, affect the dispersion and decay of fugitive emissions. A retrospective study of a pooled analysis of risk with various aerosol-generating procedures showed that healthcare professionals had a significantly greater risk of infection with intubation and non-invasive manual ventilation than nebulizers. ${ }^{62}$ A filter can be attached to the outlet of a nebulizer to capture exhaled aerosol droplets during aerosol therapy. ${ }^{45,63,64}$ However, it is essential to note that the efficiency of these filters in the prevention of coronavirus transmission is not known due to the lack of clinical studies in this area of research. ${ }^{22}$

Since nebulizer contamination plays a vital role in the transmission of the virus and the risk of infection, cleaning nebulizers after each treatment and adhering to infection control procedures during aerosol therapy is essential in this global pandemic. While mesh nebulizers should be cleaned based on the manufacturer's guidelines, jet nebulizers should be rinsed, air-dried, and/or disinfected after each therapy. ${ }^{65-67}$ Also, it is essential to keep in mind that the virus may persist in droplets in the air if a contaminated nebulizer is used for aerosol drug delivery to patients with COVID-19. Therefore, aerosol therapy should be administered in a location such as outside on a patio, porch, or in a garage, where the air is not circulated into the house, to minimize exposure to non-infected family members. ${ }^{9}$ Exhaled air in the room should be replaced with fresh air from outside. Frequent airing and cross ventilation are just as effective as leaving the windows open. Air purifiers may reduce the concentration of aerosol particles in a room and have the same effect as ventilation with clean outside air. While three to six air changes per hour are commonly used in air purifiers, the higher exchange rate will reduce the existing particle concentration faster during this global pandemic. If the clean air delivery rate is $750 \mathrm{~m}^{3} / \mathrm{h}$, the infection risk/hour of time spent in a room with an infected person can be decreased to $10 \% .{ }^{68}$ Air purifiers should be placed in a location where they can freely draw the room air and distribute the purified air evenly throughout the room. ${ }^{69}$ Therefore, they should not be placed behind furniture or under tables. Air purifiers have several disadvantages such as noise emissions of the fan, cost, and power consumption that may reduce their acceptance in daily life. ${ }^{70}$ Also, changing the filter of air purifiers regularly is necessary to keep their efficiency. In the use of air purifiers, it is still essential to 
keep using other protective measures such as wearing a mask, social distancing, and ventilation.

Patients should also stay isolated in one room and avoid not only shared space but also personal household items such as dishes, towels, or bedding as much as possible. ${ }^{71}$ If shared spaces had to be used, they should stay at least $1 \mathrm{~m}$ away from others, ${ }^{9,71,72}$ wear a face mask when near to family members, and change the face mask every day. ${ }^{71}$ Keeping distance from other family members will help dilute exhaled bioaerosols containing the virus; therefore, the probability of disease transmission to other family members will decrease. The use of facemasks will decrease the concentration of exhaled bioaerosols in the room by filtering them during breathing, speaking, coughing, or sneezing. It is also important to note that using a face shield without a face mask is not effective in infection control because exhaled bioaerosols containing the pathogen flow unfiltered around the shield. Usually, face shields are used to prevent droplet infection via the mucous membranes of the eyes. Similarly, Plexiglas barriers that are designed for homecare are ineffective in preventing the spread of infected bioaerosols indoors because they serve as spit and splash protection against large particles. When coughing and sneezing, patients should also cover their nose and mouth with a tissue that needs to be thrown away immediately. ${ }^{71,72}$ Cleaning oftentouched surfaces in their separate room, washing hands with soap and water for 20 seconds and using an alcoholbased hand sanitizer that contains at least $\% 60$ alcohol are important to prevent the spread of infection. ${ }^{71}$ Otherwise, poor compliance with infection control procedures and exposure to the virus will be an issue for uninfected family members. It is also essential to provide training to caregivers to decrease the risk of exposure to the virus while caring for someone with COVID-19. The World Health Organization have excellent guidelines on home care and infection control for patients with COVID-19. ${ }^{71}$

Due to a novel, highly transmissible virus, many countries have implemented infection control measures to isolate or quarantine individuals infected with or exposed to coronavirus. Also, policymakers placed regulations on social distancing and lockdowns to protect the most vulnerable. Patients and their caregivers should follow the doctor's recommendations about their treatments and home isolations. To improve the health and well-being of patients with COPD at home, telemedicine can be utilized for disease management, patient monitoring, and evaluation, as well as the training of patients and caregivers on optimum aerosol drug delivery and infection control in the era of COVID-19. Although telemedicine has faced some barriers such as cost, regulation, technological and equipment challenges in the past, advances in technology and recent healthcare reforms have reduced these barriers. Therefore, the prevalence of telemedicine is increasing in the era of COVID-19. While some studies on telemedicine show improvements in patient outcomes, satisfaction, hospital admission rates, anxiety, and depression in $\mathrm{COPD},{ }^{73-83}$ others reported no significant improvements ${ }^{82-86}$ The conflicting results on the previous studies may be due to the high variability of patients evaluated, the severity of the disease, the types of technology, and service lines used in these studies. According to previous research, telemedicine can reduce the number of visits to primary care and emergency departments, ${ }^{73-76,81,87,88}$ provide better disease management ${ }^{73,76,78,79,83,87}$ bolsters patient-clinician relationship, ${ }^{77,85,89,90}$ and increase patient empowerment and engagement in COPD. ${ }^{73,75,76,89,90}$ Also, it is useful in enhancing access to care during home isolations and lockdowns as well as in rural areas where access to care may be restricted. Previous research showed improvements in COPD and reductions in hospital admissions related to exacerbations due to additional services such as videoconferencing and phone support added to the traditional COPD management through telemedicine. ${ }^{86,88}$ Also, while having access to a respiratory therapist or a nurse is a logical approach that should improve patient education and outcomes, it may increase the workload of clinicians and the cost of services provided to patients with COPD. ${ }^{77-79,85,90,91}$ Other barriers of telemedicine include lack of standardization in services, ${ }^{77,78,84,87,89}$ patients' disconcert with technology, ${ }^{79,80,87}$ less patient autonomy, ${ }^{74,85,89}$ time consuming, ${ }^{77,87}$ perceived lack of usefulness, ${ }^{90}$ and patient/ caregiver resistance on using telemedicine. ${ }^{77}$ Despite many barriers, telemedicine is still a viable option for patients with COPD because current healthcare resources are limited compared with the growing needs in the COVID-19 pandemic. Therefore, alternative strategies need to be developed to improve the clinical pathway of patients with COPD treated at home in the era of COVID-19.

\section{Conclusion}

Given the unknowns in this global pandemic, actions must be taken to ensure the resilience and well-being of patients with COPD in the era of COVID-19 and beyond. Patient education and improving access to healthcare are some of the most pressing needs in patients with COPD. Therefore, using telemedicine in this patient population is paramount, along with 
the development and implementation of creative strategies to achieve success with clinical standards and established selfmanagement practices in aerosol drug delivery to patients with COPD who are treated at home. Through the suggested treatment strategies on device selection, interface selection, delivery technique, and infection control, clinicians can provide safe and effective treatments for patients with COPD treated at home in the era of COVID-19 and beyond.

\section{Funding}

No funding was obtained in the preparation of this manuscript.

\section{Disclosure}

Dr. Ari discloses her relationship with Aerogen Ltd, Boehringer Ingelheim, and Philips Healthcare. Dr. Hanania received honoraria for serving as a consultant or advisory boards for GlaxoSmithKline, Sanofi, Regeneron, Genentech, Novartis, Boehringer Ingelheim, Astra Zeneca, Teva, Amgen, and Mylan pharmaceuticals. His institution receives research grant support from GlaxoSmithKline, Sanofi, Genentech, Gossamer Bio, Boehringer Ingelheim, Novartis, and Astra Zeneca. The authors report no other conflicts of interest in this work.

\section{References}

1. Interim U.S. Guidance for risk assessment and public health management of healthcare personnel with potential exposure in a healthcare setting to patients with coronavirus disease (COVID-19). Center for Disease Control and Prevention; 2020. Available from: https://www. cdc.gov/coronavirus/2019-ncov/hcp/guidance-risk-assesment-hcp. html. Accessed September 14, 2021.

2. Johnston SL. Overview of virus-induced airway disease. Proc Am Thorac Soc. 2005;2(2):150-156. doi:10.1513/pats.200502-018AW

3. Yin Y, Wunderink RG. MERS, SARS and other coronaviruses as causes of pneumonia. Respirology. 2018;23(2):130-137. doi:10.1111/resp.13196

4. Kerkhove V, Alaswad S, Assiri A, et al. Transmissibility of MERS-CoV infection in closed setting. Emerg Infect Dis. 2015;25:1802-1809.

5. Assaf SM, Tarasevych SP, Diamant Z, Hanania NA. Asthma and severe acute respiratory syndrome coronavirus 2019: current evidence and knowledge gaps. Curr Opin Pulm Med. 2021;27(1):45-53. doi:10.1097/MCP.0000000000000744

6. Halpin DMG, Faner R, Sibila O, Badia JR, Agusti A. Do chronic respiratory diseases or their treatment affect the risk of SARS-CoV-2 infection? Lancet Respir Med. 2020;8(5):436-438. doi:10.1016/ S2213-2600(20)30167-3

7. Recommendations for inhaled asthma controller medications. Global Initiative for Asthma; 2020. Available from: https://ginasthma.org/ recommendations-for-inhaled-asthma-controller-medications/. Accessed September 14, 2021.

8. Global Initiative for Chronic Obstructive Lung Disease (GOLD). Global strategy for the diagnosis, management and prevention of chronic obstructive pulmonary disease 2020 report; 2020. Available from: http://www.goldcopd.org. Accessed September 14, 2021.
9. Ari A. Use of aerosolised medications at home for COVID-19. Lancet Respir Med. 2020;8(8):754-756. doi:10.1016/S22132600(20)30270-8

10. Ari A, Restrepo RD. Aerosol delivery device selection for spontaneously breathing patients: 2012. Respir Care. 2012;57(4):613-626. doi: $10.4187 /$ respcare. 01756

11. Ari A, Fink J. Guidelines to aerosol devices in infants, children and adults: which to choose, why and how to achieve effective aerosol therapy? Expert Rev Respir Med. 2011;5(4):561-572. doi:10.1586/ers.11.49

12. Ari A, Fink JB. Differential medical aerosol device and interface selection in patients during spontaneous, conventional mechanical and noninvasive ventilation. J Aerosol Med Pulm Drug Deliv. 2016;29(2):95-106. doi:10.1089/jamp.2015.1266

13. DePietro M, Gilbert I, Millette LA, Riebe M. Inhalation device options for the management of chronic obstructive pulmonary disease. Postgrad Med. 2018;130(1):83-97. doi:10.1080/00325481.2018.1399042

14. Wieshammer S, Dreyhaupt J. Dry powder inhalers: which factors determine the frequency of handling errors? Respiration. 2008;75 (1):18-25. doi:10.1159/000109374

15. Jarvis S, Ind PW, Shiner RJ. Inhaled therapy in elderly COPD patients; time for re-evaluation? Age Ageing. 2007;36(2):213-218. doi:10.1093/ageing/afl174

16. Fromer L, Goodwin E, Walsh J. Customizing inhaled therapy to meet the needs of COPD patients. Postgrad Med. 2010;122(2):83-93. doi:10.3810/pgm.2010.03.2125

17. Lavorini F, Mannini C, Chellini E, Fontana GA. Optimising inhaled pharmacotherapy for elderly patients with chronic obstructive pulmonary disease: the importance of delivery devices. Drugs Aging. 2016;33(7):461-473. doi:10.1007/s40266-016-0377-y

18. Fink JB, Rubin BK. Problems with inhaler use: a call for improved clinician and patient education. Respir Care. 2005;50:1360-1374.

19. Fink JB. Inhalers in asthma management: is demonstration the key to compliance? Respir Care. 2005;50:598-600.

20. Lewis RM, Fink JB. Promoting adherence to inhaled therapy: building partnerships through patient education. Respir Care Clin $N \mathrm{Am}$. 2001;7(2):277-301,vi. doi:10.1016/S1078-5337(05)70034-4

21. Hanania NA, Braman S, Adams SG, et al. The role of inhalation delivery devices in COPD: perspectives of patients and health care providers. Chronic Obstr Pulm Dis. 2018;5(2):111-123. doi:10.15326/jcopdf.5.2.2017.0168

22. Ari A. Practical strategies for a safe and effective delivery of aerosolized medications to patients with COVID-19. Respir Med. 2020;167:105987. doi:10.1016/j.rmed.2020.105987

23. Ari A. Promoting safe and effective use of aerosol devices in COVID-19: risks and suggestions for viral transmission. Expert Opin Drug Deliv. 2020;17(11):1509-1513. doi:10.1080/17425247.2020.1811225

24. Ari A. Patient education and adherence to aerosol therapy. Respir Care. 2015;60(6):941-955. doi:10.4187/respcare.03854

25. Ari A, Fink J. Aerosol therapy in children: challenges and solutions. Expert Rev Respir Med. 2013;7(6):665-672. doi:10.1586/ 17476348.2013.847369

26. Dhand R, Mahler DA, Carlin BW, et al. Results of a patient survey regarding COPD knowledge, treatment experiences, and practices with inhalation devices. Respir Care. 2018;63(7):833-839. doi: $10.4187 /$ respcare. 05715

27. Luczak-Wozniak K, Dabrowska M, Domagala I, et al. Mishandling of pMDI and DPI inhalers in asthma and COPD - repetitive and nonrepetitive errors. Pulm Pharmacol Ther. 2018;51:65-72. doi:10.1016/ j.pupt.2018.06.002

28. Riley J, Krüger P. Optimising inhaler technique in chronic obstructive pulmonary disease: a complex issue. Br J Nurs. 2017;26(7):391-397. doi:10.12968/bjon.2017.26.7.391

29. Elbeddini A, Yeats A. Amid COVID-19 drug shortages: proposed plan for reprocessing and reusing salbutamol pressurized metered dose inhalers (pMDIs) for shared use. Drugs Ther Perspect. 2020;36:1-3. 
30. Press VG, Gershon AS, Sciurba FC, Blagev DP. Concerns about coronavirus disease-related collateral damage for patients with COPD. Chest. 2020;158(3):866-868. doi:10.1016/j.chest.2020. 05.549

31. Ari A. Jet, mesh and ultrasonic nebulizers: an evaluation of nebulizers for better clinical practice. Eurasian J Pulmonol. 2014;16:1-7.

32. Rau JL. Design principles of liquid nebulization devices currently in use. Respir Care. 2002;47:1257-1275.

33. Ari A. Effect of nebulizer type, delivery interface, and flow rate on aerosol drug delivery to spontaneously breathing pediatric and infant lung models. Pediatr Pulmonol. 2019;54(11):1735-1741. doi: $10.1002 /$ ppul.24449

34. Ari A, de Andrade AD, Sheard M, AlHamad B, Fink JB. Performance comparisons of jet and mesh nebulizers using different interfaces in simulated spontaneously breathing adults and children. J Aerosol Med Pulm Drug Deliv. 2015;28(4):281-289. doi:10.1089/ jamp.2014.1149

35. O'Toole C, McGrath J, Bennett G, Joyce M, MacLoughlin R, Byrne M. Fugitive emissions from a breath actuated jet nebuliser and a vibrating mesh nebuliser for a paediatric patient. In: ISESISIAQ 2019; 2019; Kaunas, Lithuania.

36. Mitchell JP, Nagel MW. Valved holding chambers (VHCs) for use with pressurised metered-dose inhalers (pMDIs): a review of causes of inconsistent medication delivery. Prim Care Respir J. 2007;16 (4):207-214. doi:10.3132/pcrj.2007.00034

37. Wildhaber JH, Devadason SG, Eber E, et al. Effect of electrostatic charge, flow, delay and multiple actuations on the in vitro delivery of salbutamol from different small volume spacers for infants. Thorax. 1996;51(10):985-988. doi:10.1136/thx.51.10.985

38. Wildhaber JH, Janssens HM, Pierart F, Dore ND, Devadason SG, LeSouef PN. High-percentage lung delivery in children from detergent-treated spacers. Pediatr Pulmonol. 2000;29(5):389-393. doi:10.1002/(SICI)1099-0496(200005)29:5<389::AID-PPUL8>3.0. $\mathrm{CO} ; 2-3$

39. Wildhaber J, Devadason S, Hayden M, et al. Electrostatic charge on a plastic spacer device influences the delivery of salbutamol. Eur Respir J. 1996;9(9):1943-1946. doi:10.1183/09031936.96.09091943

40. Pierart F, Wildhaber J, Vrancken I, Devadason SG, Le Souef PN. Washing spacers in household detergent reduces electrostatic charge and greatly improves delivery. Eur Respir J. 1999;13(3):673-678. doi:10.1183/09031936.99.13367399

41. Dompeling E, Oudesluys-Murphy AM, Janssens HM, et al. Randomised controlled study of clinical efficacy of spacer therapy in asthma with regard to electrostatic charge. Arch Dis Child. 2001;84 (2):178-182. doi:10.1136/adc.84.2.178

42. Anhoj J, Bisgaard H, Lipworth BJ. Effect of electrostatic charge in plastic spacers on the lung delivery of HFA-salbutamol in children. Br J Clin Pharmacol. 1999;47(3):333-336. doi:10.1046/j.13652125.1999.00893.x

43. Bisgaard H, Anhoj J, Klug B, Berg E. A non-electrostatic spacer for aerosol delivery. Arch Dis Child. 1995;73(3):226-230. doi:10.1136/ adc. 73.3 .226

44. Ari A. Drug delivery interfaces: a way to optimize inhalation therapy in spontaneously breathing children. World J Clin Pediatr. 2016;5 (3):281-287. doi:10.5409/wjcp.v5.i3.281

45. McGrath J, O'Toole C, Joyce GB, Joyce M, Byrne MA, MacLoughlin R. Investigation of fugitive aerosols released into the environment during high-flow therapy. Pharmaceutics. 2019;11 (6):254. doi:10.3390/pharmaceutics 11060254

46. Ari A. Optimizing inhalation therapy in spontaneously breathing patients. Clin Pulm Med. 2014;21(1):34-41. doi:10.1097/ CPM.0000000000000019

47. Rubin BK. Air and soul: the science and application of aerosol therapy. Respir Care. 2010;55:911-921.

48. Rau JL. 2004 Philip Kittredge Memorial Lecture. The inhalation of drugs: advantages and problems. Respir Care. 2005;50:367-382.
49. Rau JL. Practical problems with aerosol therapy in COPD. Respir Care. 2006;51:158-172.

50. McFadden ER Jr. Improper patient techniques with metered dose inhalers: clinical consequences and solutions to misuse. J Allergy Clin Immunol. 1995;96(2):278-283. doi:10.1016/S0091-6749(95) 70206-7

51. Lavorini F, Levy ML, Corrigan C, Crompton G. The ADMIT series issues in inhalation therapy. 6) training tools for inhalation devices. Prim Care Respir J. 2010;19(4):335-341. doi:10.4104/ pcrj.2010.00065

52. Chrystyn H. Is inhalation rate important for a dry powder inhaler? Using the in-check dial to identify these rates. Respir Med. 2003;97 (2):181-187. doi:10.1053/rmed.2003.1351

53. Fiato KL, Iwamoto GK, Harkins MS, Morelos J. Monitoring flow rates and retention of inhalation techniques using the in-check dial device in adult asthmatics. $J$ Asthma. 2007;44(3):209-212. doi:10.1080/02770900701209798

54. Amirav I, Newhouse MT, Mansour Y. Measurement of peak inspiratory flow with in-check dial device to simulate low-resistance (Diskus) and high-resistance (Turbohaler) dry powder inhalers in children with asthma. Pediatr Pulmonol. 2005;39(5):447-451. doi:10.1002/ppul.20180

55. van der Palen J. Peak inspiratory flow through diskus and turbuhaler, measured by means of a peak inspiratory flow meter (In-Check DIAL). Respir Med. 2003;97(3):285-289. doi:10.1053/ rmed.2003.1289

56. Saeed H, Mohsen M, Fink J, et al. Fill volume, humidification and heat effects on aerosol delivery and fugitive emissions during noninvasive ventilation. J Drug Deliv Sci Technol. 2017;39:372-378. doi:10.1016/j.jddst.2017.04.026

57. Nazaroff W. Indoor bioaerosol dynamics. Indoor Air. 2016;26 (1):61-78. doi:10.1111/ina.12174

58. Long C, Suh H, Catalano P, Koutrakis P. Using time- and size-resolved particulate data to quantify indoor penetration and deposition behavior. Environ Sci Technol. 2001;35(10):2089-2099. doi:10.1021/es001477d

59. McGrath J, Byrne M, Ashmore M, Terry A, Dimitroulopoulou C. Development of a probabilistic multi-zone multi-source computational model and demonstration of its applications in predicting PM concentrations indoors. Sci Total Environ. 2014;490:798-806. doi:10.1016/j.scitotenv.2014.05.081

60. McGrath J, Byrne M, Ashmore M, Terry A, Dimitroulopoulou C. A simulation study of the changes in PM2.5 concentrations due to interzonal airflow variations caused by internal door opening patterns. Atmos Environ. 2014;87:183-188. doi:10.1016/j. atmosenv.2014.01.050

61. Ciuzas D, Prasauskas T, Krugly E, et al. Characterization of indoor aerosol temporal variations for the real-time management of indoor air quality. Atmos Environ. 2015;118:107-117. doi:10.1016/j. atmosenv.2015.07.044

62. Tran K, Cimon K, Severn M, Pessoa-Silva C, Conly J, Semple MG. Aerosol generating procedures and risk of transmission of acute respiratory infections to healthcare workers: a systematic review. PLoS One. 2012;7(4):e35797. doi:10.1371/journal.pone.0035797

63. Wittgen BP, Kunst PW, Perkins WR, Lee JK, Postmus PE. Assessing a system to capture stray aerosol during inhalation of nebulized liposomal cisplatin. $J$ Aerosol Sci. 2006;19(3):385-391. doi:10.1089/jam.2006.19.385

64. Ari A, Scott JB. Lessons learned about aerosol drug delivery in the era of COVID-19. CHEST; 2021. Available from: https://www.chest net.org/Topic-Collections/COVID-19/COVID-in-Focus/LessonsLearned-About-Aerosol-Drug-Delivery-in-the-Era-of-COVID-19. Accessed September 14, 2021.

65. O'Malley CA. Device cleaning and infection control in aerosol therapy. Respir Care. 2015;60(6):917-927. doi:10.4187/respcare. 03513 
66. Tablan O, Anderson L, Besser R, Bridges C, Hajjeh R. Guidelines for preventing health care-associated pneumonia. Recommendations of the $\mathrm{CDC}$ and the healthcare infection control practices advisory committee. MMWR Recommendations \& Reports; 2004 [updated March 26, 2004; cited January 19, 2009]. Available from: http:/www.cdc.gov/mmwr/ preview/mmwrhtml/rr5303a1.htm. Accessed September 14, 2021.

67. Cleaning and disinfecting nebulizers. Cystic FIbrosis Foundation; 2019. Available from: https://www.cff.org/Life-With-CF/Treatments-andTherapies/Medications/Nebulizer-Care-at-Home/. Accessed September 14, 2021.

68. Kriegel M, Buchholz P, Gastmeier P, Bischoff P, Abdelgawad I, Hartmann A. Predicted infection risk for aerosol transmission of SARS-CoV-2. Medrxiv. 2020. Available from: https://www.medrxiv. org/content/10.1101/2020.10.08.20209106v5. Accessed September 14, 2021.

69. Kupper M, Asbach C, Schneiderwind U, Finger H, Spiegelhoff D, Schumacher S. Testing of an indoor air cleaner for particulate pollutants under realistic conditions in an office room. Aerosol Air Qual Res. 2019;19(8):1655-1665. doi:10.4209/aaqr.2019.01.0029

70. Pei J, Dong C, Liu J. Operating behavior and corresponding performance of portable air cleaners in residential buildings, China. Build Environ. 2019;147:473-481. doi:10.1016/j.buildenv.2018.08.009

71. Home care for patients with COVID-19 presenting with mild symptoms and management of their contacts. World Health Organization; 2020 [updated May 14, 2020]. Available from: https://www.who.int/ publications-detail/home-care-for-patients-with-suspected-novelcoronavirus-(ncov)-infection-presenting-with-mild-symptoms-andmanagement-of-contacts. Accessed September 14, 2021.

72. Fink J, Ehrmann S, Li J, et al. Reducing aerosol-related risk of transmission in the era of COVID-19. J Aerosol Med Pulm Drug Deliv. 2020;33(6):300-304. doi:10.1089/jamp.2020.1615

73. Jensen MH, Cichosz SL, Hejlesen OK, et al. Clinical impact of home telemonitoring on patients with chronic obstructive pulmonary disease. Telemed J E Health. 2012;18(9):674-678. doi:10.1089/ tmj.2012.0003

74. Sanchez-Morillo D, Fernandez-Granero MA, Jiménez AL. Detecting COPD exacerbations early using daily telemonitoring of symptoms and k-means clustering: a Pilot Study. Med Biol Eng Comput. 2015;53(5):441-451. doi:10.1007/s11517-015-1252-4

75. Alrajab S, Smith TR, Owens M, Areno JP, Caldito G. A home telemonitoring program reduced exacerbation and healthcare utilization rates in COPD patients with frequent exacerbations. Telemed $J$ E Health. 2012;18(10):772-776. doi:10.1089/tmj.2012.0005

76. Antoniades Nc, Rochford PD, Pretto JJ, et al. Pilot study of remote telemonitoring in COPD. Telemed $J$ E Health. 2012;18(8):634-640. doi:10.1089/tmj.2011.0231

77. Fairbrother P, Pinnock H, Hanley J, et al. Exploring telemonitoring and self-management by patients with chronic obstructive pulmonary disease: a qualitative study embedded in a randomized controlled trial. Patient Educ Couns. 2013;93(3):403-410. doi:10.1016/j.pec.2013.04.003

78. Ho TW, Huang CT, Chiu HC, et al. Effectiveness of telemonitoring in patients with chronic obstructive pulmonary disease in Taiwan-a randomized controlled trial. Sci Rep. 2016;6(1):23797. doi: $10.1038 /$ srep23797
79. Kim J, Kim S, Kim H, et al. Acceptability of the consumer-centric u-health services for patients with chronic obstructive pulmonary disease. Telemed J E Health. 2012;18(5):329-338. doi:10.1089/ tmj.2011.0140

80. McDowell JE, McClean S, FitzGibbon F, Tate S. A randomised clinical trial of the effectiveness of home-based health care with telemonitoring in patients with COPD. J Telemed Telecare. 2015;21 (2):80-87. doi:10.1177/1357633X14566575

81. Pedone C, Lelli D. Systematic review of telemonitoring in COPD: an update. Pneumonol Alergol Pol. 2015;83(6):476-484. doi:10.5603/ PiAP.2015.0077

82. Reddel HK, Jenkins CR, Partridge MR. Self-management support and other alternatives to reduce the burden of asthma and chronic obstructive pulmonary disease. Int J Tuberc Lung Dis. 2014;18 (12):1396-1406. doi:10.5588/ijtld.14.0371

83. Venter A, Burns R, Hefford M, Ehrenberg N. Results of a telehealth-enabled chronic care management service to support people with long-term conditions at home. J Telemed Telecare. 2012;18 (3):172-175. doi:10.1258/jtt.2012.SFT112

84. Burton C, Pinnock H, McKinstry B. Changes in telemonitored physiological variables and symptoms prior to exacerbations of chronic obstructive pulmonary disease. $J$ Telemed Telecare. 2015;21 (1):29-36. doi:10.1177/1357633X14562733

85. Chatwin M, Hawkins G, Panicchia L, et al. Randomised crossover trial of telemonitoring in chronic respiratory patients (TeleCRAFT trial). Thorax. 2016;71(4):305-311. doi:10.1136/thoraxjnl-2015207045

86. Vianello A, Fusello M, Gubian L, et al. Home telemonitoring for patients with acute exacerbation of chronic obstructive pulmonary disease: a randomized controlled trial. BMC Pulm Med. 2016;16 (1):157. doi:10.1186/s12890-016-0321-2

87. Elwyn G, Hardisty AR, Peirce SC, et al. Detecting deterioration in patients with chronic disease using telemonitoring: navigating the 'trough of disillusionment'. J Eval Clin Pract. 2012;18(4):896-903. doi:10.1111/j.1365-2753.2011.01701.x

88. Martín-Lesende I, Orruño E, Bilbao A, et al. Impact of telemonitoring home care patients with heart failure or chronic lung disease from primary care on healthcare resource use (the TELBIL study randomised controlled trial). BMC Health Serv Res. 2013;13(1):118. doi:10.1186/1472-6963-13-118

89. Davis C, Bender M, Smith T, Broad J. Feasibility and acute care utilization outcomes of a post-acute transitional telemonitoring program for underserved chronic disease patients. Telemed $J$ E Health. 2015;21(9):705-713. doi:10.1089/tmj.2014.0181

90. Fairbrother P, Pinnock H, Hanley J, et al. Continuity, but at what cost? The impact of telemonitoring COPD on continuities of care: a qualitative study. Prim Care Respir J. 2012;21(3):322-328. doi:10.4104/pcrj.2012.00068

91. Stoddart A, van der Pol M, Pinnock H, et al. Telemonitoring for chronic obstructive pulmonary disease: a cost and cost-utility analysis of a randomised controlled trial. $J$ Telemed Telecare. 2015;21 (2):108-118. doi:10.1177/1357633X14566574

\section{Publish your work in this journal}

The International Journal of COPD is an international, peer-reviewed journal of therapeutics and pharmacology focusing on concise rapid reporting of clinical studies and reviews in COPD. Special focus is given to the pathophysiological processes underlying the disease, intervention programs, patient focused education, and self management protocols. This journal is indexed on PubMed Central, MedLine and CAS. The manuscript management system is completely online and includes a very quick and fair peer-review system, which is all easy to use. Visit http://www.dovepress.com/testimonials.php to read real quotes from published authors. 